\title{
ANALISIS KEBIJAKAN COMPLIANCE RISK MANAGEMENT BERBASIS MACHINE LEARNING PADA DIREKTORAT JENDERAL PAJAK
}

\author{
Tia Diamendia* \\ Fakultas Ilmu Administrasi Universitas Indonesia, Jakarta \\ tia.diamendia@gmail.com \\ Milla S. Setyowati \\ Fakultas Ilmu Administrasi Universitas Indonesia, Jakarta \\ milla.s.setyowati@gmail.com
}

*Alamat Korespondensi: tia.diamendia@gmail.com

\begin{abstract}
Implementation of tax self-assessment system gives full trust to taxpayers to calculate, pay, and report their tax themselves. To get the optimum result, the implementation of this system is determined by the level of compliance of the taxpayers. It is affected by internal and external factors such as technology, resources, legislation where the tax authority operating, organization's aim and strategy, and public general tax conformity. This study aim to analyze taxpayer conformity level with machine based Compliance Risk Management (CRM) policy. This study is using qualitative approach through interview with people who have roles in implementing tax policy in Indonesia. This study founds the importance of machine learning based CRM policy, in which the tax authority cannot apply the same treatment to all taxpayers, so it needs to decide which taxpayer needs to be investigated with rational justification based on risk level. Tax authority needs to focus on implementing big data analytics with machine learning algorithm as an important source of information in decision making process, and helps predict taxpayers with potential fraud, so it can be used to reduce task risk before it happens.
\end{abstract}

KEYWORDS: Big Data Analytics, Compliance Risk Management, Machine Learning

\begin{abstract}
ABSTRAK
Penerapan sistem self-assessment pajak memberi kepercayaan penuh dari pemerintah kepada wajib pajak untuk menghitung, menyetorkan, dan melaporkan sendiri jumlah pajak yang terhutang. Untuk mencapai hasil yang optimal, penerapan sistem ini sangat ditentukan oleh tingkat kepatuhan dari para wajib pajak. Kepatuhan dipengaruhi oleh faktor internal dan eksternal seperti teknologi, sumber daya dan keterampilan, kerangka kerja legislatif di mana badan penerimaan beroperasi, tujuan dan strategi organisasi, dan sikap masyarakat terhadap kepatuhan pajak. Studi ini bertujuan untuk menganalisis tingkat kepatuhan wajib pajak dengan kebijakan Compliance Risk Management (CRM) berbasis machine learning. Studi ini menggunakan pendekatan kualitatif dengan melakukan wawancara terhadap narasumber yang berperan dalam penerapan kebijakan pajak di Indonesia. Hasil penelitian dari studi ini adalah pentingnya kebijakan CRM berbasis Machine Learning yang pada prinsipnya bahwa setiap wajib pajak tidak dapat diperlakukan sama, sehingga diperlukannya keputusan untuk memilih wajib pajak yang diperiksa harus didasarkan pada justifikasi yang rasional berdasarkan tingkat risiko. Otoritas pajak perlu fokus dalam pemanfatan big data analytics dengan alogaritma machine learning sebagai sumber informasi penting dalam pengambilan keputusan, dan membantu memprediksi pola wajib pajak yang berpotensi menggelapkan pajak dan yang taat membayar pajak, dan dapat digunakan untuk mengurangi risiko sebelum terjadi.
\end{abstract}

KATA KUNCI: Big Data Analytics; Compliance Risk Management; Machine Learning

KLASIFIKASI JEL:

$\mathrm{H} 2, \mathrm{H} 3$

CARA MENGUTIP:

Diamendia, T., \& Setyowati, M. S. (2021). Analisis kebijakan compliance risk management berbasis machine learning pada Direktorat Jenderal Pajak. Indonesian Treasury Review: Jurnal Perbendaharaan, Keuangan Negara dan Kebijakan Publik, 6(3), 289-298. 


\section{PENDAHULUAN}

Penerapan Compliance Risk Management (CRM) pada Direktorat Jenderal Pajak (DJP) Kementerian Keuangan RI bertujuan untuk membantu DJP mencapai tujuan strategis organisasi dengan memanfaatkan suatu alat bantu (tools) pengambilan keputusan. Implementasi CRM dapat membantu DJP dalam menangani Wajib Pajak dengan lebih adil dan transparan, manajemen sumber daya menjadi lebih efektif dan lebih efisien sehingga pada akhirnya akan mewujudkan paradigma kepatuhan yang baru bagi DJP yaitu kepatuhan yang berkelanjutan.

Menurut Organization of Economic CoOperation and Development (OECD), CRM adalah proses terstruktur untuk secara sistematis mengidentifikasi, mengukur, dan mengatasi risiko kepatuhan pajak seperti tidak terdaftarnya wajib pajak, tidak melaporkan pajak dengan benar, dan lain sebagainya (OECD, 2004). Sebagaimana manajemen risiko pada umumnya, CRM merupakan proses yang berulang yang mencakup langkah-langkah untuk terus memperbaiki pengambilan keputusan oleh otoritas pajak. Penerapan CRM erat kaitannya dengan implementasi Cooperative Compliance, yaitu kebijakan dari Otoritas Pajak untuk membangun hubungan dengan wajib pajak besar yang berdasarkan kepercayaan dan kerja sama, untuk memastikan wajib pajak mematuhi aturan pajak yang berlaku.

Meskipun penerapan CRM untuk meningkatkan kepatuhan pajak sudah banyak dilaksanakan di negara lain dengan hasil yang positif, penerapannya di Indonesia sendiri baru dilaksanakan belakangan ini pada DJP, melalui Surat Edaran Direktorat Jenderal Pajak nomor SE24/ PJ/ 2019 tentang implementasi Compliance Risk Management dalam Kegiatan Ekstensifikasi, Pengawasan, Pemeriksaan, dan Penagihan pada DJP.

Studi ini mengambil fokus pada penerapan kebijakan CRM pada DJP dengan basis machine learning dan dampaknya pada manajemen risiko perpajakan secara umum. Studi ini tidak menganalisis lebih dalam mengenai dampak atas kebijakan tersebut kepada masing-masing jenis pajak yang ada pada DJP.

Studi ini juga diharapkan dapat memberi kontribusi baik secara akademik maupun secara implementasi di lapangan. Secara akademis, studi ini diharapkan dapat melengkapi studi-studi sebelumnya mengenai penerapan teknologi dalam perpajakan, terutama dalam hal pengolahan big data dan penerapan Machine Learning. Secara implementasi, studi ini diharapkan dapat menjadi

\section{PENERAPAN DALAM PRAKTIK}

- Pengawasan pajak di Indonesia terkendala oleh terbatasnya sumber daya dan banyaknya wajib pajak yang harus diawasi.

- Penerapan Compliance Risk Management yang berbasis Machine Learning dapat membantu fokus pengawasan atas wajib pajak

referensi bagi otoritas perpajakan di Indonesia dalam menerapkan sistem CRM yang berbasis Machine Learning untuk mengurangi risiko perpajakan dan meningkatkan penerimaan pajak.

\section{STUDI LITERATUR}

Menurut OECD dalam laporan "Tax Administration 2019", pengelolaan administrasi pajak telah beralih ke administrasi elektronik dengan menggunakan berbagai alat teknologi, sumber data, dan analisis data untuk meningkatkan kepatuhan pajak (OECD, 2019). Sehubungan dengan hal itu, menurut Wolfers (2018) secara umum teknologi yang dapat membantu perpajakan dapat dibagi menjadi empat, yaitu: solusi mengenai compliance yang membantu dalam hal pelaporan pajak, solusi mengenai insight yang membantu mengidentifikasi potensi risiko pajak, solusi mengenai process management yang membantu mengelola proses tertentu dalam perpajakan, dan infrastruktur yang memungkinkan implementasi ketiga solusi sebelumnya. Studi ini akan lebih memfokuskan pada solusi mengenai insight dengan menggunakan teknologi Machine Learning untuk mengidentifikasi dan meminimalisir potensi risiko ketidakpatuhan pembayaran pajak.

Dengan banyaknya aktivitas ekonomi digital yang tidak tercatat secara formal (shadow economy), sejumlah negara mengatasi tantangan ini dengan mengimplementasikan big data analytics. Pemerintah Inggris misalnya telah sukses mengembalikan pendapatan pajak sebesar US\$5.4M. Tingginya volume transaksi digital melalui e-commerce dan multichannel pembayaran dapat diurai dalam big data analytics. Big data analytics merupakan kumpulan data yang sangat besar yang membutuhkan supercomputer untuk memproses dan menganalisis sehingga menghasilkan simpulan yang berarti (Moorthy et al., 2015).

Algoritma machine learning dalam big data analytics akan mempelajari tren dan pola seluruh wajib pajak dengan didukung oleh data yang melimpah. Big data analytics akan membantu memprediksi pola wajib pajak yang berpotensi menggelapkan pajak dan taat membayar pajak. 
Badan pajak akan mudah memitigasi risiko penggelapan pajak sebelum hal itu terjadi.

Dalam penelitian yang dilakukan oleh Kirchler (2014) dalam jurnal yang berjudul "Cooperative Tax Compliance: from detterance to defference" (Kirchler et al., 2014), peneliti menemukan beberapa variabel psikologi yang memiliki pengaruh terhadap kepatuhan membayar pajak pada individu, seperti: social norm, knowledge, attitude, dan fairness. Peneliti melihat trust sebagai faktor psikologis yang konsisten mempengaruhi tingkah laku kepatuhan membayar pajak. Namun, peneliti tetap menyatakan bahwa peran sistem audit dan denda yang ketat tetap perlu ditegakkan. Sebuah model yang ditawarkan oleh Kirchler, Hoelzl, \& Wahl (2008) bernama slippery-slope tax compliance, yang mengintegrasikan faktor ekonomi dan psikologi. Dua variabel yang mempengaruhi tax compliance adalah power dan trust. Hasil secara konsisten menunjukan bahwa pengaruh faktor trust lebih besar dibandingkan dengan power. Menariknya, tingkat tax compliance lebih besar ditemukan pada individu yang lebih tua dan individu yang memiliki tingkat pendidikan yang lebih tinggi (Kirchler et al., 2008).

Dalam jurnal lain yang berjudul "Behavioural insight of tax compliance: An overview of recent conceptual and empirical approaches", (Biddle, 2019) membahas mengenai keputusan wajib pajak untuk mengecilkan pajak mereka yang dilatarbelakangi oleh seberapa besar kemungkinan dilakukan pemeriksaan dan seberapa besar sanksi yang mungkin dikenakan akibat pelanggaran sanksi. Indikator utama untuk memprediksi model penolakan/ deterrence model adalah peningkatan kepatuhan sebagai hasil dari peningkatan tarif pajak; keberhasilan dalam mendeteksi penghindaran pajak; tingkat penalti untuk penghindaran pajak; dan profil risiko dari pembayar pajak. Dua bidang penting dalam penelitian ini, yaitu: pertama adalah teori tanggung jawab sosial perusahaan; kedua adalah pentingnya sistem hukum suatu negara dalam mempengaruhi kepatuhan.

Tahapan dalam melakukan Compliance Risk Management, seperti yang digambarkan pada gambar 1.

\section{Identify Risk}

Risiko dapat diidentifikasi dengan pendekatan top down seperti dengan analisis makro ekonomi, maupun dengan pendekatan bottom up seperti penilaian risiko secara kasus per kasus. Dalam mengidentifikasi risiko, badan pajak perlu untuk melakukan segmentasi wajib pajak dengan baik dan benar, sehingga dapat dilakukan analisa perilaku berdasarkan masing-masing segmen.

\section{Assess \& Prioritize Risk}

Badan pajak perlu untuk mengembangkan kriteria yang tepat untuk dapat secara objektif mengevaluasi besarnya risiko kepatuhan dalam konteks menentukan prioritas penanganan risiko. Pengukuran dan penetapan prioritas perlu untuk dilakukan berdasarkan bukti-bukti yang objektif.

\section{Analyze Compliance Behavior}

Berdasarkan studi empiris, ada beberapa faktor yang dapat menjelaskan perilaku kepatuhan dari wajib pajak. Alasan wajib pajak tidak patuh adalah karena beberapa faktor, diantaranya: umur, tingkat pendidikan, gender, industri, persepsi atas biaya kepatuhan pajak, dan risiko jika tidak mematuhi pajak. Konsekuensi dari ketidakpatuhan pajak, seperti ancaman hukuman dan tuntutan dapat mempengaruhi perilaku kepatuhan pajak dari wajib pajak. Dampak lainnya, studi menunjukkan bahwa wajib pajak yang patuh ingin agar wajib pajak yang tidak patuh agar dihukum. Pemberian insentif bagi wajib pajak juga dapat memberi efek positif bagi perilaku kepatuhan wajib pajak, walaupun perlu studi lanjutan untuk menemukan bukti empirisnya.

\section{Determine Treatment Strategies}

Program kepatuhan pajak perlu untuk menyediakan respon yang baik atas perilaku kepatuhan pajak, sehingga memberi kemudahan bagi wajib pajak yang mau mematuhi pajak dan menetapkan penegakan hukum bagi wajib pajak yang tidak mau mematuhi pajak. Strategi yang diterapkan untuk mengatasi ketidakpatuhan pajak

\section{Gambar 1.Proses Compliance Risk Management}

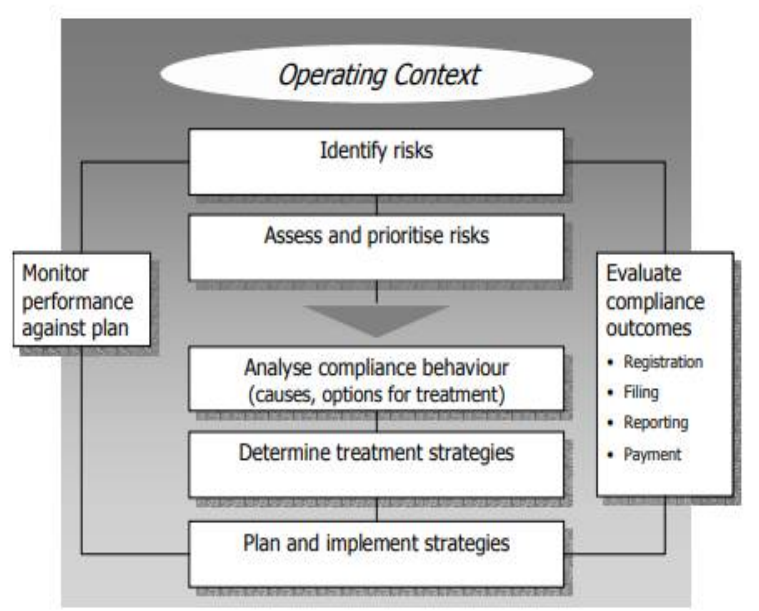

Sumber: OECD 
harus dapat mengatasi faktor pendorong dari munculnya perilaku tersebut.

\section{Plan and Implement Strategies}

Langkah pertama dalam menetapkan strategi adalah memastikan bahwa wajib pajak memahami kewajiban pajaknya dan memahami bahwa kewajiban pajak tersebut mudah untuk dipenuhi. Dari sisi badan pajak, amat penting untuk selalu bertindak dengan penuh integritas, adil dan masuk akal untuk mendorong wajib pajak secara sukarela mematuhi kewajiban pajaknya. Untuk dapat lebih mempengaruhi perilaku kepatuhan wajib pajak, seringkali diperlukan aliansi strategis dengan badan atau lembaga lain, asosiasi industri, dan penasihat atau konsultan pajak. Strategi yang telah dipilih harus diimplementasikan dengan menggunakan sumber daya yang tersedia secara efektif dan efisien.

\section{Evaluate Compliance Outcomes}

Dalam penerapan strategi perpajakan, perlu untuk ditetapkan indikator untuk mengevaluasi sukses atau tidaknya suatu strategi. Tujuan dari penerapan suatu strategi harus tidak hanya berorientasi pada hasil jangka pendek, tetapi lebih ke perubahan perilaku dari wajib pajak.

\section{METODE PENELITIAN}

Pendekatan penelitian yang peneliti gunakan dalam penelitian ini adalah pendekatan penelitian kualitatif yang memiliki arah penalaran induktif. Peneliti hendak menjabarkan fenomena sosial dengan mengutamakan realita-realita sosial yang ditemukan pada penelitian. Melalui pendekatan kualitatif, peneliti ingin memusatkan pada konteks yang dapat menggambarkan dan membentuk pemahaman dari permasalahan yang sedang diteliti serta mengembangkan teori yang digunakan dalam penelitian ini. Melalui penalaran induktif, peneliti ingin melakukan analisis terhadap kebijakan CRM berbasis machine learning pada DJP.

Secara garis besar, teknik pengumpulan data ditujukan untuk mengumpulkan data dan informasi yang diperlukan untuk menjawab pertanyaan-pertanyaan penelitian yang diajukan peneliti sehingga pertanyaan tersebut bisa dijawab secara objektif. Metodologi teknik pengumpulan data digolongkan menjadi tiga kelompok, yaitu: quantitative methodology, qualitative methodology, dan mixed methodology (Kawulich, 2012).

Peneliti menggunakan pendekatan mixed methodology dalam teknik pengumpulan data. Hal ini dikarenakan secara mayoritas teknik pengumpulan data peneliti menggunakan pendekatan metodologi kualitatif berupa penggalian dalam bentuk kata-kata dalam data untuk menjelaskan fenomena sosial yang terjadi, diiringi dengan teknik pengumpulan data minoritas berupa analisis interpretasi data berupa angka dalam dokumen-dokumen relevan yang didapatkan untuk menjadi pertimbangan analisis data kualitatif yang didapatkan.

Studi kepustakaan digunakan oleh selama pelaksanaan penelitian. Data-data hasil studi kepustakaan digunakan untuk melengkapi data dari studi lapangan (field research) agar konsepkonsep yang relevan terhadap topik penelitian dapat dipahami secara mendalam oleh peneliti dari awal penelitian (sebelum turun ke lapangan) sekaligus menjadi salah satu alat bantu dalam melakukan analisis data yang didapatkan setelah turun ke lapangan.

Sebagai peneliti sosial, peneliti meyakini bahwa studi lapangan merupakan hal utama dalam penelitian sosial sehingga realita dalam lapangan bisa didapatkan sebenar-benarnya. Dalam studi lapangan ini, peneliti melakukan wawancara terhadap pihak yang berkaitan langsung dengan permasalahan penelitian. Wawancara mendalam ditujukan untuk lebih menggali keseluruhan topik penelitian. Peneliti memberikan kebebasan kepada para informan untuk menjelaskan sesuai pandangannya terkait kebijakan CRM pada DJP .

Wawancara mendalam dalam penelitian ini dilakukan kepada pihak-pihak terkait isu, tujuan, dan rumusan masalah penelitian. Pihak yang diwawancarai peneliti adalah pihak DJP dan Pihak Akademisi. Wawancara dengan pihak DJP dilakukan dengan Kepala Pusat Data dan Informasi DJP, Kepala Bidang Pemeriksaan DJP, dan juga seksi yang terkait dengan pelaksana compliance risk management untuk mengetahui bagaimana desain compliance risk managemet yang diterapkan pada DJP dalam menambah tingkat kepatuhan wajib pajak, serta kelebihan dan kelemahan sistem yang sudah berjalan.

Wawancara terhadap praktisi dilakukan untuk mendapatkan informasi mengenai praktek compliance risk management. Praktisi yang dipilih berasal dari Danny Darussalam Tax Center (DDTC) atau Center for Indonesia Taxation Analysis (CITA), dengan target informasi adalah bagaimana pengetahuan dan pendapat praktisi terhadap pemungutan pajak yang telah dilakukan.

\section{HASIL DAN PEMBAHASAN}

\section{Hasil}

Pengembangan CRM pada DJP dilatarbelakangi oleh lemahnya Decision Support 
System berbasis data, analisa berbasis data yang kurang optimal, alokasi sumber daya terbatas dan beban kerja yang tinggi, rendahnya pemahaman atas perilaku kepatuhan wajib pajak, serta adanya kebutuhan proses yang sistematis untuk identifikasi risiko kepatuhan wajib pajak dalam memastikan kepatuhan wajib pajak dapat dilakukan secara lebih objektif, transparan, dan adil. Pemahaman yang disertai dengan alokasi sumber daya yang tepat diharapkan mampu mendorong tingkat kepatuhan wajib pajak.

Implementasi CRM ini memperhatikan risikorisko fundamental yang menjadi pemengaruh dalam upaya wajib pajak menjalankan kewajiban perpajakannnya, yaitu risiko pendaftaran (registration), risiko pelaporan (filing), risiko pembayaran pajak (payment), dan risiko kebenaran pelaporan (correct reporting). Seluruh tahapan dalam proses CRM tersebut diarahkan untuk meningkatkan kepatuhan dan kepuasan Wajib Pajak yang lebih tinggi. Lebih lanjut, pemetaan risiko dan penanganannya yang terdeferensiasi bertujuan untuk memberikan keadilan dan meningkatkan transparansi dalam penanganan wajib pajak, manajemen sumber daya menjadi lebih efektif dan lebih efisien sehingga pada akhirnya akan mewujudkan paradigma kepatuhan yang baru bagi DJP yaitu kepatuhan yang berkelanjutan (sustainable compliance).

Untuk meningkatkan kepercayaan antara otoritas pajak dan wajib pajak, terdapat alat bantu yang bernama Tax Control Framework (TCF), yang merupakan bagian dari sistem internal kontrol wajib pajak yang berfungsi memastikan keakuratan dan kelengkapan dari pembayaran dan pelaporan pajak yang dilakukan oleh wajib pajak tersebut (Goslinga et al., 2019). TCF yang disiapkan wajib pajak diserahkan ke otoritas pajak yang menilai dan menguji implementasi TCF tersebut. Ketika hasil pengujian menunjukkan ketidaksesuaian, wajib pajak diberikan pengarahan dan otoritas pajak harus secara intens melakukan komunikasi (OECD, 2016). Hal ini disebabkan TCF pada dasarnya merupakan alat bagi otoritas pajak untuk melakukan kerja sama dengan wajib pajak. Jadi, wajib pajak tidak langsung diberikan hukuman ketika hasilnya tidak sesuai dengan ekspektasi otoritas pajak.

Pada implementasi CRM, input dari manajemen risiko masih berupa data dari sistem pelaporan dan pembayaran DJP, dan informasi wajib pajak badan yang diinput secara manual oleh pegawai pajak. Pelaksanaan TCF, dimana wajib pajak badan memiliki data online yang terintegrasi dengan DJP, baru diaplikasikan secara terbatas pada beberapa Badan Usaha Milik Negara (BUMN).
Salah satu BUMN yang telah menerapkan TCF adalah PT Pertamina (Persero), sehingga DJP dapat langsung menilai berapa pajak yang harus dibayar, dan berapa yang sudah disetor oleh wajib pajak tersebut. Penerapan TCF ini sebenarnya juga menguntungkan wajib pajak, karena dengan terintegrasinya data, dapat mempermudah proses restitusi pajak bagi wajib pajak. Namun demikian masih banyak wajib pajak yang enggan untuk membuka data keuangannya kepada DJP. DJP perlu melakukan sosialisasi mengenai kelebihan dari pengintegrasian data keuangan wajib pajak dengan DJP, sehingga implementasi TCF di DJP dapat berjalan dengan baik.

\section{Pembahasan}

Compliance Risk Management berbasis Machine Learning pada DJP.

Identify Risk

Pendekatan yang dilakukan untuk mengidentifikasi risiko kepatuhan wajib pajak adalah dengan mengkombinasikan analisis laporan keuangan, keterkaitan antara data internal dan eksternal, expert judgement, stakeholder's experience di lapangan yang diolah secara kuantitatif dengan pembobotan dan metode statistik tertentu. Dalam laporan yang diterbitkan tahun 2016, OECD berkesimpulan bahwa ketika TCF dari sebuah perusahaan multinasional yang berpartisipasi dalam program cooperative compliance berjalan dengan efektif, dan ketika perusahaan tersebut menyediakan keterbukaan informasi tentang risiko pajak secara transparan kepada badan penerimaan negara, maka review dan audit yang dilakukan terhadap pelaporan pajak dari perusahaan tersebut dapat berkurang secara signifikan. Badan penerimaan negara dapat mengandalkan pelaporan pajak dari perusahaan tersebut dan percaya bahwa segala macam permasalahan pajak yang dimiliki perusahaan tersebut telah disampaikan. Guidance note compliance risk management: managing and improving tax compliance (2004) menyebutkan bahwa risiko dapat di identifikasi menggunakan teknik top-down seperti analisis makro ekonomi atau teknik bottom-up seperti penilaian risiko secara kasus per kasus.

Dalam melakukan identifikasi risiko kepatuhan, faktor-faktor yang mempengaruhi kepatuhan antara lain: pemahaman wajib pajak akan peraturan perpajakan, pemahaman wajib pajak terhadap aplikasi dan instrumen yang digunakan untuk melaporkan SPT, kemudahan wajib pajak dalam menunaikan kewajiban perpajakannya, serta pengawasan yang terintegrasi baik secara vertikal maupun horizontal 
dalam melakukan pengawasan terhadap pemenuhan kewajiban perpajakan agar tercapai kepatuhan. Menurut Adesina Olugoke Oladipupo hasil penelitiannya menunjukkan bahwa pengetahuan perpajakan berpengaruh signifikan terhadap kepatuhan pajak, sedangkan pinalti (sanksi) tidak berpengaruh signifikan terhadap kepatuhan pajak (Oladipupo \& Obazee, 2016).

Di Indonesia, kebijakan pengelolaan risiko kepatuhan pajak telah dilakukan oleh DJP melalui Peraturan Menteri Keuangan (PMK) Nomor 191/ PMK.09/ 2008 tentang Penerapan Manajemen Risiko di Lingkungan Departemen Keuangan. Secara spesifik, berkaitan dengan tax compliance risk management, DJP menerbitkan Surat Edaran Nomor SE-24/PJ/2019 tentang Implementasi Compliance Risk Management (CRM) dalam Kegiatan Ekstensifikasi, Pengawasan, Pemeriksaan, dan Penagihan pada DJP.

Direktorat Jenderal Pajak telah mengidentifikasi risiko dengan melakukan segmentasi wajib pajak, dimulai dengan mengelompokkan berdasarkan wajib pajak badan, wajib pajak orang pribadi karyawan dan orang pribadi non karyawan. Proses memetakan sasaran prioritas CRM pemeriksaan dimulai dari melakukan identifikasi variabel yang menjadi indikator ketidakpatuhan Wajib Pajak. Kemudian melalui serangkaian komputasi data dan variabel akan didapatkan rumus kalkulasi untuk menentukan score dan bobot dari setiap variabel, hasil pemodelannya disebut risk engine, hasil data dari setiap wajib pajak dimasukan ke dalam risk engine sehingga didapatkan tingkat risiko kepatuhan setiap wajib pajak (peta kepatuhan). Output dari identifikasi risiko, dibagi menjadi tiga, yaitu risiko rendah, risiko menengah, dan risiko tiggi.

Proses identifikasi risiko yang dilakukan DJP masih kurang optimal karena hanya mengandalkan pemetaan data oleh pegawai internal DJP. Keterbatasan sumber daya di DJP yang belum sebanding dengan banyaknya jumlah wajib pajak yang harus diawasi membuat DJP lebih fokus kepada wajib pajak besar dalam melakukan identifikasi risiko, padahal sangat mungkin risiko pajak yang tinggi ada pada wajib pajak pribadi atau perusahaan berskala kecil, yang walaupun nilainya kecil namun jumlah wajib pajaknya besar, sehingga secara total menyebabkan risiko pajak yang tidak sedikit. Seperti yang disebutkan dalam laporan OECD tahun 2016, implementasi TCF yang efektif dan berjalan dengan baik akan secara signifikan mengurangi review dan audit yang harus dilakukan oleh otoritas pajak atas pelaporan pajak oleh wajib pajak. Saat ini penerapan TCF di DJP baru terbatas pada salah satu BUMN terbesar di Indonesia, yaitu
PT Pertamina (Persero). Untuk itu, DJP sebaiknya mulai memprioritaskan implementasi TCF di Indonesia, untuk dapat lebih efektif melakukan identifikasi risiko perpajakan.

\section{Assess and Prioritize Risk}

Penilaian risiko pada lingkungan DJP didasarkan pada identifikasi peristiwa-peristiwa atau variabel data historis yang diindikasikan akan berpengaruh terhadap risiko kepatuhan wajib pajak. Variabel-variabel diolah secara kuantitatif untuk menentukan sumbu $\mathrm{x}$ dan sumbu y pada peta risiko. Kemudian pengolahan data dilakukan untuk mencari range/ sebaran serta bobot dari setiap variabel berdasarkan expert judgement untuk selanjutnya dioleh menjadi peta risiko. Pengolahan data dikembangkan menggunakan social network analysis menghasilkan big data analysis menggunakan alogaritma machine learning.

Machine Learning merupakan salah satu cabang dari ilmu Artificial Intelligence yang digunakan untuk mengolah data dalam jumlah besar menjadi informasi yang dapat membantu dalam proses pengambilan keputusan. Penerapan machine learning sudah digunakan dalam berbagai bidang kehidupan, baik untuk keperluan bisnis, dunia kesehatan maupun Pemerintahan. Beberapa contoh penggunaan machine learning dalam kehidupan sehari-hari di antaranya adalah rekomendasi produk pada online marketplace, iklan pada website google, deteksi transaksi mencurigakan pada bank, dan self driving car. Menurut Khrisnan (2013) machine learning dapat didefinisikan sebagai penemuan pengetahuan baru oleh mesin dimana mesin tersebut berpikir dan merespon dengan cara menyerupai teknik dan cara belajar manusia dan hewan. Keunggulan terbesar dalam menerapkan machine learning adalah aspek otomasi dalam hal memperkaya ilmu pengetahuan dengan teknik selflearning dimana dalam prosesnya hanya menggunakan sedikit sekali intervensi manusia.

Penerapan CRM membutuhkan tools berupa aplikasi machine learning karena berkaitan dengan banyaknya data yang harus diolah oleh otoritas pajak. Sejak tahun 2012, DJP telah menggunakan aplikasi approweb yang merupakan aplikasi yang menyandingkan data internal dan data eksternal yang digunakan sebagai tools untuk melakukan pengawasan terhadap wajib pajak. Tujuan utama penggunaan aplikasi approweb adalah dalam rangka pengamanan penerimaan pajak melalui pengawasan kepatuhan dan penggalian potensi terhadap pajak wajib pajak secara efektif, terintegrasi, dan berkesinambungan. 
Approweb menggunakan input dari data internal dan data eksternal. Data internal mencakup data yang terkandung dalam SPT Tahunan, SPT Masa, dan Laporan Keuangan yang dilaporkan wajib pajak dan data olahan turunannya seperti data ekualisasi, riwayat pemeriksaan pajak, dan lain sebagainya. Sedangkan data pihak ketiga meliputi analisis data pihak ketiga dan data lainnya (seperti data realtime perusahaan, data industri, tarif, pertukaran dengan data badan pajak di luar negeri, perbankan, data rekanan pemerintah, kerja sama dengan marketplace seperti tokopedia dan lain sebagainya). Tujuannya adalah untuk mengidentifikasi potensi wajib pajak yang memiliki nilai transaksi di atas threshold pajak namun belum memiliki NPWP.

Gambar 2. Risiko Ketidakpatuhan DJP

\begin{tabular}{|c|c|c|}
\hline \multicolumn{3}{|l|}{$X$} \\
\hline $\mathrm{X} 1 \mathrm{Y3}$ & X2Y3 & X3Y3 \\
\hline $\mathrm{X} 1 \mathrm{Y} 2$ & $\mathrm{X} 2 \mathrm{Y} 2$ & X3Y2 \\
\hline $\mathrm{X1Y1}$ & $\mathrm{X} 2 \mathrm{Y} 1$ & X3Y1 \\
\hline
\end{tabular}

$\mathrm{X}$ : Probabilitas Ketidakpatuhan Y: Dampak Fiskal

Sumber: wawancara

Output dari approweb adalah pengelompokan wajib pajak berdasarkan tingkat kepatuhannya. Wajib pajak dengan tingkat kepatuhan tinggi dilakukan pengawasan kewajiban rutin, wajib pajak dengan kepatuhan menengah dilakukan pengawasan kewajiban pembayaran rutin atas seluruh jenis pajak, dan jika tidak kooperatif dapat diusulkan pemeriksaan. Sedangkan wajib pajak dengan tingkat kepatuhan rendah akan dilakukan pengawasan atas seluruh jenis pajak dan jika tidak kooperatif akan diusulkan pemeriksaan pajak/ pemeriksaan bukti permulaan/penyidikan di bidang perpajakan. Gambar 2 menunjukkan bahwa semakin tinggi kemungkinan ketidakpatuhan, maka semakin tinggi pula dampak fiskalnya, begitu pula sebaliknya. Wajib pajak yang berada di kuadran X3Y3 memiliki risiko dan dampak fiskal yang tinggi dan menjadi fokus CRM fungsi pemeriksaan.

Implementasi approweb di lingkungan DJP merupakan salah satu contoh penerapan machine learning, dimana approweb mempelajari pola-pola tertentu dari sistem pembayaran dan pelaporan pajak untuk melakukan klasifikasi wajib pajak berdasarkan risiko kepatuhannya. Hasil pengklasifikasian tersebut membantu proses pengambilan keputusan dalam hal menentukan wajib pajak mana yang perlu dilakukan pemeriksaan dan wajib pajak mana yang sudah dinilai cukup patuh sehingga tidak perlu dilakukan pemeriksaan. Dengan diterapkannya approweb, Account Representative DJP dapat melihat tingkat kepatuhan dari wajib pajak yang ditanganinya, sehingga mempermudah proses tindak lanjut wajib pajak berisiko tinggi.

Meskipun penerapan machine learning melalui aplikasi approweb sudah cukup membantu proses identifikasi risiko, namun pengaplikasiannya masih dapat ditingkatkan dengan mengintegrasikan approweb dengan sistem eksternal, seperti perizinan usaha baru di Pemerintah Daerah, data perbankan, online marketplace, dan sumber data lainnya yang dapat memberikan gambaran secara lebih utuh mengenai potensi wajib pajak baru dan tingkat risiko dari wajib pajak eksisting. Sesuai dengan definisi machine learning bahwa mesin/sistem dapat belajar sendiri seperti manusia (Simon et al., 2016), dengan adanya integrasi sistem dengan pihak eksternal, maka sistem approweb akan dapat mempelajari hal baru dari data-data eksternal, tanpa harus diinput secara manual oleh pegawai DJP. Berdasarkan hasil wawancara yang dilakukan dengan pegawai DJP, diketahui bahwa kedepannya sistem approweb memang diarahkan untuk dapat terintegrasi dengan data-data eksternal, sehingga diharapkan akan semakin meningkatkan kualitas output yang dihasilkan oleh approweb.

Menurut Kepala Seksi Keberatan dan Banding Kantor Pelayanan Pajak WP Besar, Didit Hariyanto, pada tahap awal data eksternal yang dibutuhkan adalah integrasi data antar instansi pemerintah dan BUMN. Dengan terintegrasinya laporan keuangan BUMN dengan DJP, perhitungan pajak dapat dilakukan lebih cepat dan akurat, sehingga mempermudah wajib pajak dalam melakukan restitusi pajak. Saat ini baru BUMN PT Pertamina (Persero) yang telah mengintegrasikan sistem keuangannya dengan DJP. Saat ini sistem approweb sedang dalam tahap awal untuk mengintegrasikan sistem dengan pihak eksternal.

\section{Analyze Compliance Behavior}

Analisa perilaku yang dilakukan oleh DJP dilakukan berdasarkan lama terdaftar, jenis usaha, tingkat omset, social network analysis, dan lain sebagainya. Dengan mempelajari perilaku wajib pajak dan diolah menggunakan CRM yang menghasilkan peta kepatuhan, salah satu nya adalah analisis laporan keuangan, seperti analisis terhadap rasio-rasio keuangan, keterkaitan data, data benchmark berdasarkan industri atau jenis usaha yang semuanya ditampilkan dalam aplikasi 
internal. Atas wajib pajak yang sudah ditentukan kriteria kepatuhan (Gambar 2) tindak lanjut tetap dilakukan berdasarkan prosedur pengawasan dan pemeriksaan yang berlaku, dimana Account Representative (AR) terlebih dahulu menerbitkan surat penjelasan atas data dan/atau keterangan (SP2K). Jika setelah diterbitkan SP2K WP terindikasi tidak patuh, maka AR melakukan analisis risiko untuk selanjutnya dilakukan pemeriksaan pemeriksaan pajak/pemeriksaan bukti permulaan/ penyidikan di bidang perpajakan.

Menurut Webley dalam Value Added Tax Compliance in the United Kingdom (Webley et al., 2002), alasan perilaku ketidakpatuhan adalah (1) sistem perpajakan memperlakukan wajib pajak tidak adil antara satu dengan yang lain, (2) adanya peluang unttuk tidak patuh, (3) Mereka yang tidak patuh cenderung merupakan lelaki, lebih muda, egois dan memiliki sikap positif terhadap penghindaran pajak dan sikap negatif terhadap otoritas pajak (4) Norma sosial : Jika seseorang percaya bahwa ketidakpatuhan pajak berlaku secara luas, mereka akan sangat mungkin untuk tidak patuh, (5) Ketidakpuasan terhadap otoritas pajak. Ada bukti yang menunjukkan bahwa pengetahuan wajib pajak terhadap sistem perpajakan memiliki dampak langsung untuk mengurangi kecenderungan menghindari pajak.

Berdasarkan teori Webley tersebut, terlihat bahwa DJP perlu untuk meningkatkan keterbukaan informasi perpajakan kepada publik, untuk meningkatkan kepercayaan terhadap DJP dan memberikan kejelasan kepada wajib pajak mengenai keadilan perhitungan pajak dan kebermanfaatan dari dana pajak yang terkumpul untuk pembangunan negara. DJP juga harus secara aktif mengedukasi masyarakat mengenai sistem perpajakan di Indonesia agar meningkatkan pemahaman mengenai pengenaan pajak, sehingga timbul kesadaran untuk membayarkan dan melaporkan pajak.

\section{Determine Treatment Strategies}

Dalam menetapkan strategi meningkatkan kepatuhan wajib pajak di DJP, dukungan manajemen puncak sangat penting dalam perumusan kebijakan, monitoring, dan determinasi dalam pengambilan keputusan. Berdasarkan output machine learning untuk wajib pajak dengan tingkat kepatuhan rendah dilakukan penegakan hukum secara tegas dengan melakukan pemeriksaan khusus, pemeriksaan bukti permulaan, dan penyidikan di bidang perpajakan. Wajib pajak dengan tingkat kepatuhan sedang dilakukan pengawasan wajib pajak secara melekat terhadap seluruh kewajiban perpajakannya dengan melakukan pendekatan secara persuasif. Wajib pajak dengan tingkat kepatuhan tinggi dilakukan pengawasan kewajiban rutin terhadap seluruh jenis pajak.

Menurut pedoman OECD Compliance Risk Management: Managing and Improving Tax Compliance (2004) program kepatuhan harus memberikan kemudahan atas wajib pajak yang patuh, dan tegas atas wajib pajak yang tidak patuh. Hal ini telah diterapkan dengan baik di DJP, dimana wajib pajak dengan tingkat kepatuhan yang baik akan diberikan reward berupa dibebaskan dari pemeriksaan dan pemberian penurunan denda keterlambatan dari $2 \%$ menjadi 0,5\%, sedangkan akan dilakukan pemeriksaan atas wajib pajak yang berisiko tinggi. Sebelum dilakukan pemeriksaan atas wajib pajak yang tidak patuh, DJP akan menghimbau kepada wajib pajak agar memperbaiki pelaporan, jika himbauan tersebut tidak dipenuhi, baru dilakukan pemeriksaan, dan dapat dikenakan sanksi perpajakan. Pengecualian pemeriksaan dan pengenaan sanksi dapat diberikan kepada wajib pajak yang tidak patuh dikarenakan adanya permasalahan likuiditas, ketidak patuhan akibat kesalahan pihak lain, belum paham aturan (umumnya pada wajib pajak baru), dan akibat adanya huru-hara dan bencana non alam.

\section{Plan and Implement Strategies}

Menurut pedoman OECD, bahwa penerapan efektif dari strategi kepatuhan tergantung kepada tiga kunci: sumber daya, desain strategi, dan eksekusi dari pelaksanaan. Badan pajak bertanggungjawab kepada pemerintah dan masyarakat untuk menghemat biaya yang dikeluarkan untuk memungut pajak dalam rangka mencapai target kepatuhan. Dalam mendesain stretegi, badan pajak perlu mengikutsertakan industri yang relevan atau segmen pasar, perantara pajak (seperti kantor akuntan publik, kantor hukum, konsultan pajak dan institusi keuangan), serta petugas pajak dalam rangka kolaborasi proses. Pada saat mengeksekusi strategi, badan pajak perlu memastikan bahwa implementasi dari strategi telah direncanakan dengan sangat baik, dikelola, dan di komunikasikan, dalam prosesnya menunjukkan standar profesionalisme yang tinggi. Kemampuan ini tidak bisa diterima begitu saja, harus dipupuk kesadarannya. Menurut Agung Darono pada jurnal teknik informatika dan sistem informasi (Darono et al., 2020), analytics data diharapkan dapat memperkecil kesenjangan (gap) antara jumlah pajak yang dibayarkan dengan jumlah pajak yang seharusnya dibayarkan oleh wajib pajak. 
Beberapa kajian menunjukkan bahwa kebanyakan otoritas pajak telah menggunakan pendekatan mereka antara lain dengan menggunakan kepatuhan pajak kooperatif dan juga pemeriksaan pajak berbasis risiko pada keandalan aplikasi data analytics. Menurut Nico Aditya, pegawai Sekretariat Jenderal Kementerian Keuangan, dalam tulisannya yang berjudul "ekstensifikasi/intensifikasi pajak menggunakan big data, mungkinkah?" disampaikan bahwa pemanfaatan big data diyakini pemerintah akan mendapatkan informasi mengenai kegiatan ekonomi calon wajib pajak/ wajib pajak. Informasi tersebut dapat digunakan untuk profiling data wajib pajak berdasarkan pola lokasi, penggunaan pulsa per bulan, transaksi pada toko online, sampai dengan pola frekuensi serta intensitas komunikasi melalui jaringan internet. Dengan demikian terdapat celah bagi pemerintah untuk mengupayakan ekstensifikasi data melalui pemanfaatan big data.

Strategi DJP dalam rangka meningkatkan kepatuhan wajib pajak adalah mendorong wajib pajak untuk memanfaatkan berbagai fasilitas pelayanan secara daring tanpa tatap muka dengan menggunakan aplikasi-aplikasi berbasis website dan DJP senantiasa berusaha memudahkan, memberikan pelayanan terbaik, dan melakukan pelayanan berbasis compliance risk management dengan mengedepankan prinsip continuous improvement terhadap seluruh layanan DJP menuju kepatuhan yang berkelanjutan.

Untuk mempercepat pemanfaatan pelaporan pajak secara daring, DJP sejak tahun 2014 telah menggalakkan program efiling melalui Peraturan Direktur Jenderal Pajak nomor PER-1/PJ/2014, yang mendorong masyarakat untuk melakukan pelaporan secara online melalui efiling. Penerapan program efiling ini dibarengi juga dengan peningkatan kapasitas sumber daya manusia DJP dan teknologi sistem informasi efiling yang mudah digunakan dan dapat diandalkan, sehingga benarbenar memberi kemudahan bagi wajib pajak yang akan menggunakannya. Hal ini sudah sesuai dengan pedoman OECD mengenai 3 kunci keefektifan dari strategi kepatuhan pajak, yaitu sumber daya (SDM dan IT), desain strategi (mendorong penggunaan efiling), dan eksekusi dari pelaksanaan (Sistem efiling yang handal dan mudah digunakan).

\section{Evaluate Compliance Outcomes}

Sejak tahun 2019 kebijakan CRM sampai dengan tahun 2020, jumlah wajib pajak yang dilakukan pemeriksaan belum turun secara signifikan disebabkan jumlah wajib pajak yang sangat besar sehingga dampak dari penggunaan CRM membutuhkan rentang waktu yang lebih panjang, tetapi pengawasan berbasis CRM memberikan tingkat penerimaan pajak yang lebih besar dan lebih fokus terhadap variabel-variabel ketidakpatuhan wajib pajak. Pada tahap awal implementasi perfungsi CRM dilakukan untuk mempermudah dan mempercepat pengembangan CRM (devide and conquer). Kedepannya akan dilanjutkan dengan integrated CRM sehingga dapat melihat risiko wajib pajak secara holistik. Evaluasi pencapaian CRM fungsi Pengawasan dan Pemeriksaan dilakukan setiap tahunnya, sedangkan monitoring dilakukan secara terus menerus. Untuk meningkatkan fungsi dan kapabilitas DJP secara keseluruhan saat ini sedang dilakukan pembaruan sistem inti administrasi perpajakan.

Menurut pedoman OECD, evaluasi untuk mengukur tingkat kepatuhan wajib pajak orang pribadi dan badan perlu dipertimbangkan untuk menilai sejauh mana kepatuhan wajib pajak mungkin telah berubah dari waktu ke waktu sebagai hasil dari strategi kepatuhan melalui CRM. DJP perlu mengembangkan sistem evaluasi yang baik agar dapat menilai keefektifan dari penerapan CRM di lingkungan DJP dalam meningkatkan kepatuhan wajib pajak.

\section{KESIMPULAN}

DJP dengan kebijakan CRM sejak tahun 2019 mampu meningkatkan kepatuhan wajib pajak dan penerimaan pajak serta mengurangi biaya pemungutan. Pengawasan dan pemeriksaan fokus pada wajib pajak yang tidak patuh yang sudah dilakukan analisa menggunakan analisis prioritas berdasarkan "big data analytics" dengan pengolahan data menggunakan alogaritma machine learning melalui aplikasi approweb. Diharapkan dengan adanya profil wajib pajak berdasarkan tingkat risiko, badan pajakdapat meningkatkan pengawasan dan memberikan insentif kepada wajib pajak yang patuh, memberikan pemahaman mengenai peraturan kepada wajib pajak yang kurang patuh yang melakukan kesalahan karena ketidaktahuan terhadap peraturan, dan bertindak tegas terhadap wajib pajak yang sengaja melakukan penggelapan

\begin{tabular}{lccc}
\hline \multicolumn{1}{c}{ Nama IKU } & $\begin{array}{c}\text { Realisasi } \\
2018\end{array}$ & $\begin{array}{c}\text { Realisasi } \\
2019\end{array}$ & $\begin{array}{c}\text { Realisasi } \\
2020\end{array}$ \\
\hline Persentase tingkat & $71 \%$ & $73 \%$ & $77,63 \%$ \\
kepatuhan penyampaian & & & \\
SPT Tahunan PPh Wajib & & & \\
Pajak Badan dan Orang & & & \\
Pribadi & & & \\
\hline Sumber: Aplikasi Mandor & &
\end{tabular}


pajak, serta dilakukan evaluasi terus menerus atas hasil kepatuhan yang sudah dilakukan melalui kebijakan CRM.

Kedepannya diharapkan DJP memperluas basis data dengan alat bantu tax control framework, dan bekerja sama dengan otoritas yang berpengaruh terhadap wajib pajak seperti konsultan pajak, konsultan hukum dan sebagainya. Dengan begitu, diharapkan rencana mempercepat proses restitusi dengan e-audit dapat terlaksana dan berdampak pada tingkat kepercayaan wajib pajak terhadap otoritas pajak yang tinggi, dan menghasilkan kepatuhan wajib pajak yang tinggi pula.

\section{REFERENSI}

Biddle, N. \& Marasinghe, D. (2019). Risky data: The combined effect of framing, trust and risk preferences on the intended participation in the consumer data right. Tax and Transfer Policy Institute, Working Paper 9/ 2019

D’Agosto, E., Manzo, M., Pisani, S., \& D’Arcangello, F. M. (2017). The effect of audit activity on tax declaration: evidence on small business in Italy. SAGE Journal, 4(1), 29-57.

Darono, A. (2020). Data analytics dalam administrasi pajak di Indonesia: kajian institutional arrangement. Jurnal Teknik Informatika dan Sistem Informasi, 6(2), 195211.

Devos, K. (2014). Factors influencing individual taxpayer compliance behaviour. Melbourne: Springer.

Goslinga, S., Sigle, M., \& Veldhuizen, R. (2019). Cooperative compliance, tax control frameworks and perceived certainty about the tax position in large organisations. Journal of Tax Administratin, 5(1), 41-65.

Holzinger, L. A. \& Biddle, N. (2016). Behavioural insight of tax compliance: An overview of recent conceptual and empirical approaches. Tax and Transfer Policy Institute, Working Paper 8/ 2016

Hopkin, P. (2010). Fundamentals of risk management: understanding, evaluating and implementing effective risk management [proceding]. London: Koganpage.

Kawulich, B. (2012). Doing social research: a global context. New York: McGraw Hill.

Kirchler, E. (2007). The economic psychology of tax behaviour. Cambridge University Press: New York.

Kirchler, E., Hoelzl, E., \& Wahl, I. (2008). Enforced versus voluntary tax compliance: The "slippery slope" framework. Journal of Economic Psychology, 29(2), 210-225. https:/ / doi.org/ 10.1016/j.joep.2007.05.004

Kirchler, E., Kogler, C., \& Muehlbacher, S. (2014). Cooperative tax compliance: From deterrence to deference. Current Directions in Psychological Science, 23(2), 87-92. https:/ / doi.org/ 10.1177/ 096372141351697 5

Mahmood, M. (2012). Compliance risk management strategies for tax administrations in developing countries: a case study of the Malaysian revenue authority [tesis]. University of Warwick: United Kingdom.

Mangoting, Y. (2018). Quo Vadis Kepatuhan Pajak? Jurnal Akuntansi Multiparadigma, 9(3), 451470.

Marques, J.A., Sousa, P. \& Teixeira, G. (2020). Tax audits as path to tax compliance in Portugal. European Journal on Criminal Policy and Research, 26, 457-479.

Moorthy, J., Lahiri, R., Biswas, N., Sanyal, D., Ranjan, J., Nanath, K., \& Ghosh, P. (2015). Big data: prospects and challenges. VIKALPA: The Journal for Desicion Makers, 40(1), 74-96. https:/ / doi.org/ 10.1177/ 025609091557545 0

OECD. (2004). Compliance risk management: managing and improving tax compliance. Paris: Centre for Tax Policy and Administration.

Oladipupo, A. O. \& Obazee, U. (2016). Tax knowledge, penalties and tax compliance in small and medium scale enterprises in Nigeria. IBusiness, 8(1), 1-9. https:/ / doi.org/ 10.4236/ ib.2016.81001

Simon, A., Deo, M.S., Venkatesan, S., \& Babu, R. (2015). An overview of machine learning and its applications. International Journal of Electrical Sciences \& Engineering, 1(1), 22-24.

Umar, M.A., Derashid, C., \& Ibrahim, I. (2017). What is wrong with the fiscal social contract of taxation in developing countries? A dialogue with self-employed business owners in Nigeria. SAGE Journal, 7(4), 1-11.

Webley, P., Adams, C., \& Elffers, H. (2002). VAT compliance in the United Kingdom. Canberra: Australian National University. 